\title{
Estudio del índice glicémico de tubérculos amazónicos del Perú, en adultos
}

\author{
Rosa Oriondo, Rubén Valdivieso, Enriqueta Estrada, José Olivera, Doris Delgado \\ Centro de Investigación de Bioquímica y Nutrición, Facultad Medicina, UNMSM. Lima, Perú. \\ rosa.oriondo@gmail.com
}

Objetivos: Determinar el índice glicémico (IG), azúcares reductores y caracterización del almidón en los tubérculos amazónicos del Perú.

Diseño: Estudio descriptivo, transversal, prospectivo.

Institución: Centro de investigación de Bioquímica y Nutrición, Facultad de Medicina, UNMSM, Lima, Perú.

Participantes: Personas adultas sanas.

Material biológico: Tubérculos amazónicos: Dale-dale, Sachapapa y Pituca.

Intervenciones: Se determinó IG de los tubérculos amazónicos en personas. En los tubérculos: contenido de azúcares reductores y porcentaje de amilosa y amilopectina del almidón.

Principales medidas de resultados: Glicemia en personas adultas sanas; azúcares reductores y porcentaje de amilosa y amilopectina en los tubérculos,

Resultados: Los IG fueron: Dale dale $98,2 \%$, sachapapa 100,2\% y pituca $98,9 \%$. Contenido de azúcares reductores: Dale dale $0,391 \%$ $\mathrm{p} / \mathrm{p}$, sachapapa $0,567 \% \mathrm{p} / \mathrm{p}$, pituca $0,296 \% \mathrm{p} / \mathrm{p}$. El contenido de amilosa ( $\% \mathrm{p} / \mathrm{p}$ ) en el almidón de los tubérculos fueron: Dale dale $10,9 \%$ p/p, sachapapa $12,6 \%$ p/p y pituca $11,6 \%$ p/p.

Conclusiones: Los IG de los tubérculos estudiados fueron altos, muy cercano al de la glucosa estándar. El tubérculo de mayor IG fue la sachapapa, probablemente por su mayor contenido de azúcares reductores y mayor porcentaje de amilosa.

Palabras clave: Índice glicémico, azúcares reductores, amilosa, amilopectina, tubérculos amazónicos.

\section{Estilos alimentarios practicados por alumnos del segundo año de las EAP de Enfermería y Nutrición de la Facultad de Medicina de la Universidad Nacional Mayor de San Marcos, 2012}

\author{
Yadira Cairo, Lilia Ponce, Ronny Galarza, Américo Pacheco, Jovita Silva, \\ Edinson Sánchez y Miguel Milla \\ EAP de Nutrición, Facultad de Medicina, UNMSM. Lima, Perú. \\ ylcairo@yahoo.es
}

Objetivos: Establecer diferencias en los estilos alimentarios en alumnos del segundo año de las EAP de Enfermeria y Nutricion de la Facultad de Medicina de la UNMSM, 2012.

Diseño: Descriptivo observacional de corte transversal.

Institución: D.A.de Nutrición de la Facultad de Medicina de la UNMSM.

Participantes: Alumnos de pregrado de ambos sexos, 46 de la Escuela de Nutrición y 46 de la Escuela de Enfermería, pertenecientes al segundo año.

Intervenciones: Explorar los estilos alimentarios que practican los estudiantes universitarios de ciencias de la salud. Se aplicó un cuestionario de 87 preguntas respecto a rutinas alimentarias, tipos de alimentos y formas de consumo.

Principales medidas de resultados: Patrones alimentarios.

Resultados: Los alumnos de la EAP Enfermeria tuvieron un ligero mayor consumo de alimentos fuente de proteinas $57,3 \%$, ligero mayor consumo de alimentos fuente de minerales $52,1 \%$. Los alumnos de Nutricion tuvieron un mejor consumo de alimentos fuente de fibra $61,2 \%$. No hubo diferencia entre ambos grupos en consumo de carbohidaratos. La forma de cocciòn de alimentos en ambos grupos fue la adecuada.

Conclusiones: Los patrones alimentarios respecto a las comidas principales practicados por ambos grupos implicaron omisión 0 reemplazo de una o más de estas comidas. No se encontró diferencia significativa en los estilos alimentarios practicados por los alumnos de segundo año de las EAP de Enfermeria y Nutrición.

Palabras clave: Estilos alimentarios, comida ràpida, alimentos chatarra. 